\title{
A sociabilidade das pessoas travestis e transexuais na perícia social
}

\section{The transsexual people's sociability and transvestites in the social expertise}

\author{
Thais Felipe Silva dos Santos ${ }^{a}$ \\ (1) https://orcid.org/0000-0001-7207-578X \\ Maria Lúcia Martinellib \\ (D) https://orcid.org/0000-0001-9124-2846
}

\begin{abstract}
In search of legal recognition of gender identify, transgender and travestite appel to the Judiciary and fpr that they can pass though social skills. Acting on these demands from a social perspective brings the discussion to the cultural fiel. This article engage with the juridical social workers in the process of rectification/ change of name and legal sex of transgender people. To build the report we use several aspects, being, sociability.
\end{abstract}

Keywords: Social skills. Oral history. Social expertise.

\section{Introdução}

a busca pelo reconhecimento legal de sua identidade de gênero, as pessoas travestis e transexuais recorrem ao Judiciário e para isso podem passar por perícias sociais.

O objetivo deste artigo é discutir a atuação do assistente social judiciário nos processos de retificação de nome e sexo jurídico. Dentre os vários aspectos

aTribunal de Justiça SP — São Paulo/SP, Brasil.

bNúcleo de Estudos e Pesquisa sobre Identidade da Pontifícia Universidade Católica de São Paulo — São Paulo/SP, Brasil.

Recebido: 14/6/2018 - Aprovado: 9/10/2018 
observados para elaboração do laudo social em processos de retificação de nome e sexo jurídico, destacaremos a sociabilidade em algumas de suas vertentes. A presente pesquisa parte da atuação em processos que ingressaram na seção técnica de Serviço Social do Fórum Central no período de 2015 a 2018.

Cumpre-nos, desde logo, esclarecer que sexo jurídico é aquele contido no assentamento registral. Trata-se do sexo civil indicado no momento de lavratura do registro do recém-nascido de acordo com os caracteres biológicos, do sexo aparente, segundo Ventura (2010).

O cenário do qual falamos é o jurídico e as alterações pleiteadas são desse âmbito, ou seja, documentais, pois entendemos que socialmente a pessoa já se expressa e se identifica com o gênero por ela requerido.

Para chegarmos à construção do laudo social, somos colocados em contato com os sujeitos do caso concreto em análise, e na perspectiva teórica que nos orienta um e outro são afetados pelas reflexões produzidas numa relação dialética.

Em junho de 2018, o Conselho Nacional de Justiça possibilitou também às pessoas transgêneros alterar nome e sexo jurídico de forma cartorial.

Vale a pena lembrar que existe em tramitação o Projeto de Lei n. 5.002/2013 — Lei João Nery, de autoria do deputado João Wyllys (PSOL-RJ) e da deputada Érika Kokay (PT-DF) que dispõe sobre o direito à identidade de gênero e altera o artigo 58 da Lei n. 6.015 de 1973. ${ }^{1}$

0 projeto de lei tem aspecto abrangente, contempla, além da retificação do nome e sexo jurídico, a liberdade para realizar ou não modificações

1 Os artigos 58 e 59 de 1973 previam: Art. 58. Qualquer alteração posterior de nome só por exceção e motivadamente, após audiência do Ministério Público, será permitida por sentença do juiz a que estiver sujeito o registro, arquivando-se o mandado e publicando-se a alteração pela imprensa.

Art. 59. 0 prenome será imutável.

Posteriormente o artigo 58 passa a conter a seguinte modificação:

Art. 58. O prenome será definitivo, admitindo-se, todavia, a sua substituição por apelidos públicos notórios. (Redação dada pela Lei n. 9.708, de 1998.)

Parágrafo único. A substituição do prenome será ainda admitida em razão de fundada coação ou ameaça decorrente da colaboração com a apuração de crime, por determinação, em sentença, de juiz competente, ouvido o Ministério Público. (Redação dada pela Lei n. 9.807, de 1999.) 
corporais, as retificações em diplomas, Carteira Nacional de Habilitação, o matrimônio anterior, o uso de espaços como os banheiros, o alistamento militar, entre outros aspectos.

Segundo Tenório (2017), em diversos países existem várias formas para a realização da retificação de nome e sexo jurídico, algumas balizadas por decisões judiciais, diagnósticos médicos e cirurgias, e outras pela autodeclaração da pessoa transgênero de forma notarial, ou seja, no cartório.

Consideramos necessário o respeito à diversidade de gênero para assegurar a autonomia, a cidadania, e a não discriminação, na busca da promoção dos direitos humanos em consonância com o Código de Ética do/a Assistente Social. ${ }^{2}$

Conforme Demier (2016, p. 17-18), "o conservadorismo presente nas instituições [...] possui um significativo lastro social", e em que pese o lugar onde se dá a atuação profissional, a intervenção realizada pelo Serviço Social local busca romper com a ideia-matriz correntemente atribuída ao Judiciário, de poder coercitivo e conservador. Se essas alegações podem ser, na maioria das vezes, assertivas, também é adequado pontuar que existem profissionais nesse espaço que promovem o enfrentamento ao conservadorismo do Judiciário e valem-se das três dimensões da prática profissional para traçar estratégias de resistência. Nós não passamos indiferentes frente às questões que se expressam nas varas da família e em consonância com o artigo $8^{\circ}$, alíneas "c" e "d", do Código de ética do/a assistente social comentado (2012), que normatiza a relação profissional com as instituições empregadoras e outros, buscamos resistir.

Art. $8^{\circ}[\ldots]$

b) empenhar-se na viabilização dos direitos sociais dos/as usuários/as, através dos programas e políticas sociais;

2 Princípios fundamentais do Código de ética do/a assistente social comentado, em seu inciso VI refere o "Empenho na eliminação de todas as formas de preconceito, incentivando o respeito à diversidade, à participação de grupos socialmente discriminados e à discussão das diferenças" (Código de ética do/a assistente social, 2011, p. 23). 
c) contribuir para a alteração da correlação de forças institucionais, apoiando as legítimas demandas de interesse da população usuária; [...]. (Barroco e Terra, 2012, p. 186-187)

Portanto, fazemos do espaço sócio-ocupacional um lugar de lutas revolucionárias em favor das liberdades democráticas ao contribuir com a autodeterminação do sujeito. Desta forma, buscamos a ruptura com as bases sociais estabelecidas para tratar a questão do gênero.

\section{A sociabilidade no laudo social}

Se é que podemos afirmar que todos somos iguais perante a lei, ${ }^{3}$ um enunciado jurídico, o cotidiano nos mostra que essa norma não é factível na sociedade.

A estrutura de classes que fomenta o sexismo atua para preservar a ordem social estabelecida das relações patriarcais de gênero e cria formas de dominação-exploração também ao hierarquizar cidadãos na sociedade. Nessa visão, as pessoas travestis e transexuais são cidadãos de segunda classe - abjetas. Assim sendo, segundo Borrillo (2010, p. 31, apud Nogueira, 2018, p. 36), "[o] heterossexismo, que se define como a crença na existência de uma hierarquia das sexualidades, em que a heterossexualidade ocupa a posição superior".

Ao normatizar as relações de gênero impondo regras para o feminino e para o masculino, atua-se na preservação das relações patriarcais de gênero, as quais estão intimamente imbricadas às relações de classe. Assunção (2018, p. 59) traz uma importante reflexão: “[...] as diferenças entre homens e mulheres foram naturalizadas, e no entanto, historicamente construídas e socialmente aprofundadas".

No mesmo sentido, Cisne e Santos (2018), ao discutirem sobre as relações sociais de sexo, indicam que Butler (1993) historiciza a categoria sexo e

\footnotetext{
3 Art. $5^{\circ}$ da Constituição Federal de 1988 - Capítulo I - Dos direitos e deveres individuais e coletivos.
} 
elucida que é um processo pelo qual as normas regulatórias se materializam pela reiteração forçada de modelos preestabelecidos pelo patriarcado. E as autoras vão além, questionando a origem dessas normas e identificando sua determinação material e histórica, portanto, inseridas no sistema de exploração de classe: “[...] é a realidade, com a concretude histórica das relações sociais e seus antagonismos postos na luta de classes, que determina as normas e as ideias" (Cisne e Santos, 2018, p. 49).

O conhecimento amealhado nas perícias sociais nos permite inferir que as pessoas travestis e transexuais provocam o questionamento aos referenciais dados a partir do sexo biológico. Com o trilhar de seu percurso sócio-histórico e o conhecimento de si, as pessoas travestis e transexuais exteriorizam a identidade de gênero com o qual se reconhecem. Segundo Miskolci e Pelúcio (2007, p. 257),

[Buther] demonstrou que a performatividade se baseia na reiteração de normas que são anteriores ao agente e que, sendo permanentemente reiteradas, materializam aquilo que nomeiam. Assim, as normas reguladoras do sexo são performativas no sentido de reiterarem práticas já reguladas, materializando-se nos corpos, marcando o sexo, exigindo práticas mediante as quais se produz uma "generificação". Não se trata, portanto, de uma escolha, mas de uma coibição, ainda que esta não se faça sentir como tal. Daí seu efeito a-histórico, que faz desse conjunto de imposições algo aparentemente "natural".

A partir das transidentidades, abrem-se espaços para pensar a volatividade do masculino e do feminino como construtos culturais e variáveis no tempo histórico.

A ameaça vem do questionamento às regras estabelecidas, e conforme Jesus, Carbonieri e Nigro (2017), pontuam a fenda nas regras sociais dicotômicas que não vislumbram a diferença, que fomentam o discurso heteronormativo nas balizas biológicas.

A atuação nessas demandas, na perspectiva não patológica, traz a discussão para o campo cultural, aponta para o significado de gênero, entendido a partir de construções sociais que operam por reiteração de 
comportamentos, ao delimitar os papéis sociais na sociedade de classes, assim como sustentado por Bento (2010).

Pensar a identidade como categoria dialética implica ontologicamente considerar seus aspectos políticos e históricos, criados e recriados nas reações sociais, inserida na luta de classes e dotada das contradições inerentes à sociedade capitalista, para além da dimensão filosófica da categoria identidade, conforme ensina Martinelli (2006). Portanto, refletimos sobre uma identidade dinâmica, em construção e reconstrução permanente. É somente nas tramas das relações sociais que a identidade de gênero autodeclarada adquire concretude, é ser e ser visto como uma alteridade indispensável a sua objetivação.

A perspectiva do laudo social é demonstrar o reconhecimento social das pessoas travestis e transexuais. Por isso, na elaboração da perícia social, buscamos mediações por meio dos elementos que apontem a inserção social no mundo público e privado da pessoa, partindo do pressuposto teórico-metodológico da identidade, que pressupõe a relação do indivíduo com o meio social. Nesse sentido, Martinelli (2006, p. 11) é essencial ao apontar que:

Identidades pedem reconhecimento, reciprocidade, são construções coletivas. Não há como construir identidades de modo solitário e ninguém constrói identidade no espelho, pois ela é construída no cenário público, na vida cotidiana, juntamente com os movimentos sociais...

De antemão, elucidamos que o laudo social não tem o condão de afirmar se a pessoa é ou não transgênero, ${ }^{4}$ mas sim amealhar informações acerca do seu reconhecimento social tendo como perspectiva a identidade como cons-

4 Segundo Jesus, transgêneros são pessoas que não se identificam com o gênero que lhe foi atribuído ao nascer. (Jesus, 2012). "No Brasil, ainda não há consenso sobre o termo, vale ressaltar. Há quem se considere transgênero, como uma categoria à parte das pessoas travestis e transexuais" (Idem, p. 10).

No que se refere ao termo "travesti", Bento (2008), explica que não teria uma definição única, pode ser entendida como um terceiro gênero e, de acordo com Jesus (2012), há predomínio do feminino.

Jesus (2012), elucida que o "transexual age de acordo com o que reconhece como próprio de seu gênero: mulheres transexuais adotam nome, aparência e comportamentos femininos, querem e precisam ser tratadas como quaisquer outras mulheres. Homens transexuais adotam nome, 
trução coletiva, nos termos de Martinelli (2006). A identidade, portanto, não se prende somente às pessoas travestis e transexuais, mas é uma categoria dialética marxista de análise das relações sociais estabelecidas pelos indivíduos, pelas profissões, dentre outros aspectos. Segundo a mesma autora,

Sob o ponto de vista dialético, a identidade é uma categoria sócio histórica [grafia original] que pulsa com o tempo e com o movimento, a partir de determinações políticas, sociais, econômicas, históricas, culturais. Como categoria ético-política, cujo corolário natural é a consciência, a identidade constrói-se no fértil terreno da diferença, no interior de relações sociais antagônicas. (Martinelli, 2013, p. 145-146)

Tomando como base o pensar a sociabilidade como categoria de análise na perspectiva teórica do materialismo histórico-dialético, adotaremos a concepção apresentada por Moreira (2005, p. 95-96),

A sociabilidade é o todo formado pela integração das esferas inorgânica, orgânica e social, realizada pelo metabolismo do trabalho [em sua concepção ontológica] e orientada no sentido do salto de qualidade da história natural [...] para a história social do homem.

Nesse sentido, concordamos com Lessa (2012, p. 25) que esclarece:

A relação dos homens com a natureza requer, com absoluta necessidade, a relação entre os homens. Por isso, além dos atos de trabalho, a vida social contém uma enorme variedade de atividades voltadas para atender às necessidades que brotam do desenvolvimento das relações dos homens entre si.

Ao problematizar a atuação de assistentes sociais das varas de família, deparamo-nos, nesses processos, com elementos que emergem da sociabilidade das pessoas travestis e transexuais, da forma como se relacionam com pessoas e espaços que dão visibilidade ao gênero com o qual se identificam.

aparência e comportamentos masculinos, querem e precisam ser tratados como quaisquer outros homens" (Jesus, 2012, p. 15). 
Por isso consideramos primordial a aproximação dessas vivências para mediar e tornar singular seu cotidiano e, assim, constituir campo de análise para a construção do laudo social.

O fazer profissional em processos dessa natureza indica que apesar de as pessoas travestis e transexuais ingressarem com a retificação de nome e/ou sexo jurídico, há uma resistência em seguir os ritos processuais estabelecidos, entre eles a perícia social. As alegações são as mais diversas, desde convicções políticas até o não querer se submeter à avaliação de terceiros.

Entendemos que reivindicar a identidade construída é um ato político, mas essa reivindicação passa pelo reconhecimento do outro, bem como do Poder Judiciário, que é a instituição que tem o condão de permitir a mudança pleiteada.

$\mathrm{Na}$ atuação profissional intervimos nas tramas do tecido social e reunimos as formas de identidade dos sujeitos no processo de reprodução das relações sociais. Essa acepção não é neutra, mas é carregada do sentido que embasa o fazer profissional, intrincada pelas dimensões teórico-metodológicas e ético-políticas no sentido de prezar a liberdade como valor ético central e a emancipação do sujeito.

Guerra (2007, p. 3) ensina que "o processo de trabalho é compreendido como um conjunto de atividades prático-reflexivas voltadas para o alcance de finalidades, as quais dependem da existência, da adequação e da criação dos meios e das condições objetivas e subjetivas".

A perícia social procura desvelar a sociabilidade no âmbito das relações familiares e nos lugares de convívio social, seja de lazer, profissional, saúde, de amizades, dentre outros que possam ser apontados pelo sujeito. Contemplamos pessoas e espaços nos quais o indivíduo se relaciona, com vistas a reunir elementos que apontem a sociabilidade do sujeito num diálogo dialético com a categoria identidade - ser e ser visto. Esses contatos são imprescindíveis para a construção do laudo social no panorama não patológico.

No que tange ao mundo privado, observamos que os relatos sobre a história de vida dos sujeitos emergem de forma espontânea e rememorativa, apesar de ser um percurso íntimo e do qual muitas vezes emergem sucessivos processos de exclusão. 
Na perícia social dos processos de retificação de nome e sexo jurídico, na trajetória de vivência da identidade, verificamos o estranhamento da percepção sobre si desde tenra idade, o apreço por determinadas companhias e brincadeiras, a oportunidade de vestir-se com roupas de seu agrado quando a sós, o expressar-se livremente na infância e as interdições vindas com a puberdade. Mais tarde, a imposição de condutas ligadas ao sexo biológico, as inquietações sobre sua sexualidade, as ideações homossexuais, o contato com pessoas transexuais ou travestis e até a identificação de si com o gênero com o qual se reconhece, dentre outras nuances que compreendem os percursos singulares de cada sujeito.

Os relatos que emergiram na perícia social dos sujeitos transgêneros que ingressaram com processo de retificação de nome e/ou sexo jurídico destacaram que na sociabilidade familiar despontam narrativas da sociedade heteronormativa no sentido de disciplinar os papéis sociais como: "eu era considerada afetada", "minha mãe disse que eu poderia ser gay, mas não poderia ir à casa dela usando saia", "nos eventos de família eu queria ficar com as mulheres na cozinha e me diziam para ficar com os homens na sala", "se você não consegue me chamar pelo meu nome [aquele compatível com a identidade de gênero], pelo menos me chama de você", "meus irmãos me defendem na rua caso alguém me destrate, mas em casa eles me chamam pelo meu nome registral”, " meu irmão tinha medo de sair comigo, medo de eu ficar me jogando em cima dos homens na rua", "fecha as pernas", dentre outras vivências.

Os estudos realizados nos processos que ingressaram na Seção Técnica de Serviço Social do Fórum Central nos período de 2015 a 2018 indicam que ante os primeiros investimentos para exteriorizar o gênero com o qual se identificam, algumas famílias passam a excluir as pessoas travestis e transexuais. A exclusão familiar vulnerabiliza e pode trazer consequências para outros aspectos do ser social, quer na dimensão educacional, territorial, mercado de trabalho, entre outras dimensões da vida.

Nesse contexto, surge desde logo o espaço de violação dos direitos ao apartar, por preconceito ${ }^{5}$ e discriminação, a pessoa da convivência familiar,

5 Segundo Heller (1989, p. 47 apud CFESS/CRESS, 2006, p. 3), "os preconceitos são 'juízos provisórios refutados pela ciência e por uma experiência cuidadosamente analisada, mas que se 
tornando seu percurso sócio-histórico mais vulnerável ante a falta de rede primária ${ }^{6}$ de apoio.

Em contrapartida, alguns familiares de pessoas travestis e transexuais relatam importante fortalecimento de vínculos após a aceitação da expressão de gênero do membro familiar.

Não é raro ocorrer o desenraizamento da pessoa transgênero do território onde foi conhecida pelos determinantes do seu sexo biológico. Acompanhada da exteriorização e da expressão de gênero, vem a desterritorialização, que nos termos de Tenório (2017, p. 102-103), na tentativa de apagamento de seu passado,

Existe um fenômeno que envolve a vivência de várias pessoas transexuais, que é denominado de sealth. No sealth acontece uma espécie de "êxodo para o anonimato", em que o/a transexual, após realizar todas as intervenções corporais possíveis e a devida mudança nos documentos, muda-se de cidade e procura viver anonimato como um a pessoa não transexual dentro de um novo círculo social. $O$ anonimato da identidade transexual para muitos é significativamente importante. Sem dúvida é um sintoma de uma sociedade heterocisnormativa e preconceituosa, mas é importante preservar a autonomia das pessoas de decidir sobre sua privacidade em suas questões pessoais.

$\mathrm{Na}$ atuação profissional nos processos de natureza de retificação de nome e sexo jurídico observamos que esse desenraizamento familiar exige das pessoas travestis e transexuais a substituição de laços sociofamiliares e socioculturais que influenciaram sua constituição humana, alijando o indivíduo do direito de continuar em seu meio social de convívio (Gois, 2014).

conservam inabalados contra todos os argumentos da razão'. Nesse sentido, 'os preconceitos têm sua sustentação em bases afetivas e irracionais amparadas na desinformação, na ignorância, no moralismo, no conservadorismo e no conformismo. Numa palavra, na naturalização dos processos sociais...".

6 Segundo Lia Sanícola (2008) as redes primárias são compostas por laços de família, parentescos, amizade, vizinhança e trabalho, em união, formam uma trama de relações que confere a cada sujeito identidade e pertencimento. Geralmente representa para a pessoa um recurso precioso, as relações que se estabelecem podem originar um modo privilegiado de proteção do mundo socioafetivos e simbólico dos indivíduos. 
A imersão no mundo público da pessoa transgênero abarca as relações sociais que ela estabelece no ambiente educacional, no trabalho, no lazer e na saúde, dentre outros espaços de circulação que espelhem a identidade e a expressão de gênero requerida no processo judicial.

Muitas vezes a exclusão familiar pode acarretar também a "expulsão escolar", nos termos de Bento (2011), pois o afastamento da família em tenra idade, em que pese as proteções do Estatuto da Criança e do Adolescente, faz com que a pessoa travesti e/ou transexual deixe de frequentar a escola, situação que também reverbera na inserção no mundo do trabalho.

A atuação em processos de retificação/alteração de nome e sexo jurídico mostra que as pessoas travestis e transexuais apresentam escolarização precarizada, demonstrando a difícil, ou mesmo impossível, sociabilidade no espaço escolar. Cabe a reflexão de Bento (2011, p. 555):

A escola, que se apresenta como uma instituição incapaz de lidar com a diferença e a pluralidade, funciona como uma das principais instituições guardiãs das normas de gênero e produtora da heterossexualidade. Para os casos em que as crianças são levadas a deixar a escola por não suportarem o ambiente hostil, é limitador falarmos em "evasão". No entanto, não existem indicadores para medir a homofobia de uma sociedade e, quando se fala de escola, tudo aparece sob o manto invisibilizante da evasão. Na verdade, há um desejo de eliminar e excluir aqueles que "contaminam" o espaço escolar. Há um processo de expulsão, e não de evasão...

De forma pontual alguns/algumas conseguiram concluir o ensino superior, emergem falas sobre o ingresso e o abandono da universidade devido às violências decorrentes do gênero vivido, despontam nos relatos a dificuldade do uso do nome social nos ritos administrativos na área acadêmica. Ao mencionarmos que alguns/algumas concluíram o ensino superior, não estamos apontando a meritocracia, mas tomamos a informação mediada por processos de violências e ocultação do contexto que permeou as condições objetivas vivenciadas.

O rompimento familiar aliado à "expulsão escolar" (Bento, 2011) traz importantes desdobramentos para o mundo do trabalho. 
Emergem das perícias sociais realizadas no período de 2015 a 2018, no Fórum Central, que a inserção no mercado formal de trabalho, em grande parte dessa população, é precarizada não só pelo acesso à educação formal e qualificação devido à identidade de gênero, mas pela falta de documentação em consonância com a expressão de gênero, bem como pelo preconceito das instituições empregadoras de incluir em seus quadros pessoas travestis e transexuais.

Conforme Silva e Barbosa (2017, p. 189), "a regulação da sexualidade, gênero e identidade nascem e desenvolvem-se em diferentes espaços da nossa cultura". Portanto, também vão emergir no trabalho.

A questão da sociabilidade no trabalho tangencia as regras da cidadania mediadas pela documentação legal, e nessa vertente a transidentidade encontra a formalidade da legislação trabalhista e correlatas que trazem regramentos de como deve ser a inserção formal no mercado de trabalho. Assim, a identidade de gênero vai além da autodeclarada e da expressão de gênero e ingressa nas condições gerais da sociedade capitalista.

Nesse condão, a falta de documentação adequada à identidade de gênero é crucial, pois pode levar à exclusão do mercado de trabalho ou mesmo à não continuidade do vínculo empregatício. A ausência de documentação pode servir também para mascarar a transfobia, ao evitar a contratação pela incongruência entre gênero e documentação.

Na atuação profissional no Fórum Central, destacamos duas situações: a) ao exteriorizar a expressão de gênero, o indivíduo teve suas tarefas multiplicadas a tal ponto que não conseguiu dar conta de realizá-las e foi "demitido" por falta de eficiência; b) a pessoa ocultou sua identidade e expressão de gênero por longo tempo porque ocupava uma função preponderantemente masculina, autônoma. Ao expressar sua identidade de gênero, a pessoa deixou de ser chamada para o mercado de trabalho e passou a distribuir panfletos na via pública, situação que impactou demais sua sobrevivência.

A necessidade de materialidade da vida empurra algumas transidentidades a fazer da prostituição um meio de obtenção de renda, por vezes em tenra idade, conforme dados do Mapa de Assassinatos de Travestis e Transexuais no Brasil de 2017 elaborado pela Antra — Associação Nacional 
de Travestis e Transexuais. A rua pode ser também o lugar da acolhida, aceitação e transformação do corpo, conforme revelam Silva, Bezerra e Queiroz (2015, p. 370), ao tratar das mulheres transexuais e das travestis,

[a rua] é apresentada, [...] como um espaço receptivo, que apesar de oferecer inúmeros riscos, possibilita a construção de uma nova rede de apoio social baseada na experiência comum de vulnerabilidade. A rua apresenta-se como espaço de sociabilidade por onde elas circulam durante o dia e também espaço de trabalho à noite. Pois é através da prostituição noturna que elas encontram aqueles que parece o único meio de ter uma renda para suprirem as suas necessidades e sobreviverem.

A vivência no mercado informal de trabalho e na prostituição agrava a vulnerabilidade pessoal e social das pessoas travestis e transexuais, uma vez que as mantém à margem da sociedade, expostas a toda sorte de tribulações, em contraposição a sua autonomia e seus direitos. No limite dessas inserções trabalhistas podem levar à violência fatal.

A atuação profissional tem demonstrado que mesmo nos momentos de lazer as pessoas travestis e transexuais não estão livres para viver sua identidade de gênero de forma autônoma quando não possuem a documentação congruente com a identidade de gênero, conforme emergiram nas perícias sociais realizadas entre 2015 e 2018.

0 ingresso em "baladas" pode ser condicionado à apresentação do documento de identidade, que quando representativo da identidade e expressão de gênero, ocasiona constrangimentos e transtornos, conforme Rocha e Santos (2017).

Além disso, o uso do banheiro, nos diversos espaços de sociabilidade, não se faz de forma despreocupada. Ao contrário, pontuamos que o exercício desse direito se faz na observância dos demais usuários, os quais podem desconhecê-lo e destilar preconceitos, conforme alerta Zeger (2016).

Em sua sociabilidade, as pessoas transexuais podem ver-se em situações de constrangimento e preconceito, como exemplificado por Almeida (2018, p. 171): 
Fazer compras com um cartão de crédito, emitir um passaporte, fazer o check-in de uma passagem aérea ou terrestre, pagar um ingresso de cinema ou teatro com carteira de estudante, denunciar um agressão, adquirir um automóvel, reclamar um direito como consumidor ou trabalhador, ir a uma academia de ginástica ou ao dentista, ser sepultado(a), deixar (ou herdar) um bem ou uma pensão...

Vejamos que das atividades mais triviais do dia a dia até as consideradas complexas, os espaços de sociabilidade das pessoas travestis e transexuais podem ser dificultados pela ausência de um documento que retrate sua identidade de gênero.

Nesse contexto, vale também mencionar as amizades ou coleguismos na sociabilidade das pessoas travestis e transexuais, os quais são apontados como rede primária e que poderão corroborar com o reconhecimento social daquele indivíduo, mas, quando convidados para participar do processo judicial, declinam do convite.

Ao longo do período em que atuamos em processos de retificação de nome e sexo jurídico, alguns assistentes sociais judiciários observaram que ainda que mencionem conhecer a/o autor/a do processo, os amigos ou coleguismos revelam-se constrangidos em comparecer ao Fórum para colaborar com a pessoa. A negativa persiste mesmo ante a possibilidade de realizarmos a entrevista fora do espaço judicial; ou aceitam o convite mas não comparecem às entrevistas agendadas, limitando o universo de informações que podem auxiliar na elaboração do percurso social da pessoa transgênero.

Pelo que podemos observar na confecção do laudo social, o tratamento dispensado às pessoas travestis e transexuais é diverso no Sistema Único de Saúde. Nos locais dedicados ao chamado processo transexualizador, (2017) o acolhimento das pessoas travestis e transexuais desponta com

7 Conforme portal do Ministério da Saúde: “O objetivo é atender as pessoas que sofrem com a incompatibilidade de gênero, quando não há reconhecimento do próprio corpo em relação à identidade de gênero (masculino ou feminino). [...] A implementação do Processo Transexualizador no SUS, que regulamenta os procedimentos para a readequação sexual, se insere no contexto da Política Nacional de Saúde Integral LGBT e o desafio subsequente é a garantia do acesso a todas as pessoas que necessitam desta forma de cuidado". (2017) 
acessibilidade, mas no acesso geral da saúde em atendimento integral, básico ou especializado, os relatos trazem os constrangimentos do uso do nome registral.

Tagliamento (2015) aponta o despreparo dos profissionais de saúde no atendimento integral das pessoas travestis e transexuais, que vai além do uso do nome social e passa ao atendimento estigmatizante e preconceituoso, ao correlacionar as questões de âmbito geral da saúde com a identidade de gênero e sexualidade.

Conforme refere Almeida (2018, p. 169),

há pessoas trans que desejam mudanças corporais que modifiquem seus "caracteres sexuais secundários", bem como seus órgãos sexuais; há outras, no entanto, que não desejam qualquer modificação corporal biomédica e encontraram formas razoavelmente satisfatórias de vida. Há ainda outras que desejam realizar alguns, mas não todos os procedimentos atualmente disponíveis nas ciências biomédicas.

Do ponto de vista social no âmbito sociojurídico, a realização de procedimentos biomédicos não está atrelada ao reconhecimento social do indivíduo com vistas à retificação de nome e sexo jurídico.

Por isso entendemos e defendemos que a documentação deve representar o indivíduo, condição que o laudo social construído na perspectiva emancipatória procura contemplar, tendo como norte a efetivação dos princípios do Código de Ética "no campo democrático popular, pela construção de uma nova ordem societária” (Iamamoto, 2012, p. 42).

\section{Considerações finais}

Ao problematizar a atuação do assistente social judiciário nos processos de retificação de nome e sexo jurídico, queremos trazer a reflexão para a profissão no sentido de agarrar a temática na perspectiva social e traçar estratégias de enfrentamento a essa expressão da questão social que se apresenta. 
As dificuldades da sociabilidade mencionadas trazem diversas sequelas da questão social, como a violência, a intolerância, a desigualdade, dentre outras, resultando em processos de desumanização que, no limite, podem levar à violência fatal.

É importante destacar a dimensão política da nossa profissão, que em seus componentes éticos e técnicos buscam determinada direção societária.

$\mathrm{O}$ direito à liberdade de gênero reverbera no direito à igualdade social. Por isso, respeitar a diversidade sexual é necessário para assegurar a autonomia, a cidadania, e a não discriminação, na busca da promoção dos direitos humanos em consonância com o Código de ética do/a assistente social. $^{8}$

A realidade apresentada pelas pessoas travestis e transexuais traz à baila a importância do laudo social para o reconhecimento da identidade de gênero dos indivíduos na perspectiva de minimizar a violação de direitos. Não obstante, temos clareza que as retificações documentais não encerram as questões relacionais, sobretudo com aqueles que conheceram sua identidade biológica.

\section{Referências}

ALMEIDA, G. Identidades de gênero com ênfase nas pessoas trans: particularidades e acesso à saúde, trabalho e educação. In: NOGUEIRA, L. et al. Hasteemos a bandeira colorida: diversidade sexual e de gênero no Brasil. São Paulo: Expressão Popular, 2018.

ASSOCIAÇÃO NACIONAL DE TRAVESTIS E TRANSEXUAIS. Mapa de Assassinatos de Travestis e Transexuais no Brasil em 2017. Disponível em: <https://antrabrasil.files. wordpress.com/2018/02/relatc3b3rio-mapa-dos-assassinatos-2017-antra.pdf >. Acesso em: 15 maio 2018.

ASSUNÇÃO, I. Heterossexismo, patriarcado e diversidade sexual. In: NOGUEIRA, L. et al. Hasteemos a bandeira colorida: diversidade sexual e de gênero no Brasil. São Paulo: Expressão Popular, 2018.

8 Princípios fundamentais do Código de ética do/a assistente social comentado (2012, p. 23), em seu inciso VI, refere o "empenho na eliminação de todas as formas de preconceito, incentivando o respeito à diversidade, à participação de grupos socialmente discriminados e à discussão das diferenças". 
BARROCO, M. L. S.; TERRA, S. H. Código de ética do/a assistente social comentado. São Paulo: Cortez, 2012.

BENTO, B. O que é transexualidade. São Paulo: Brasiliense, 2008. (Primeiros passos).

As tecnologias que fazem gênero. In: VIII CONGRESSO IBEROAMERICANO DE CIÊNCIAS, TECNOLOGIA E GÊNERO. Paraná, 2010. Disponível em: <http://files.dirppg. ct.utfpr.edu.br/ppgte/eventos/cictg/conteudo_cd/E8_As_Tecnologias_que_Fazem_os_G\%C3\%AAneros.pdf $>$. Acesso em: 15 maio 2018.

. Na escola de aprende que a diferença faz diferença. Revista Estudos Feministas, Florianópolis, 2011. Disponível em: <http://www.scielo.br/pdf/ref/v19n2/v19n2a16.pdf>. Acesso em: 15 maio 2018.

BRASIL. Lei n. 6.015 de 31 de dezembro de 1973. Dispõe sobre os registros públicos e dá outras providências. Disponível em: <http://www.planalto.gov.br/ccivil_03/leis/L6015original.htm>. Acesso em: 18 abr. 2018.

. Projeto de Lei da Câmara n. 5.002/2013 — Lei João Nery. Dispõe sobre o direito à identidade de gênero e altera o artigo 58 da Lei n. 6.015 de 1973. Disponível em: <http:// www.camara.gov.br/proposicoesWeb/prop_mostrarintegra?codteor $=1059446>$. Acesso em: 18 abr. 2018.

CISNE, M.; SANTOS, S. M. M. Feminismo, diversidade sexual e Serviço Social. São Paulo: Cortez, 2018. (Biblioteca básica de Serviço Social, v. 8).

CONSTITUIÇÃO FEDERAL DE 1988. Disponível em: <http://www.planalto.gov.br/ccivil_03/ constituicao/constituicao.htm>. Acesso em: 18 abr. 2018.

CFESS/CRESS - CONSELHO FEDERAL DE SERVIÇO SOCIAL E CONSELHOS REGIONAIS DE SERVIÇO SOCIAL. Assistente Social na luta contra o preconceito: campanha pela livre orientação e expressão sexual. Brasília: CFESS, 2006. Disponível em: <http://www. cressrj.org.br/download/legislacoes/orientsexual_cress.pdf>. Acesso em: 15 maio 2018.

CONSELHO NACIONAL DE JUSTIÇA. PROVIMENTO N. 73. Disponível em: <http://www. cnj.jus.br/busca-atos-adm?documento=3503>. Acesso em: 2 out. 2018.

DEMIER, F. O barulho dos inocentes: a revolta dos “homens de bem”. In: ; HOEVELER, Rejane. A onda conservadora: ensaios sobre os atuais tempos sombrios no Brasil. Rio de Janeiro: Mauad, 2016.

GOIS, D. A. de. Famílias, desenraizamento social e privações de direitos. In:

FÁVERO, Eunice. Serviço Social e temas sociojurídicos: debates e experiências. Rio de Janeiro: Lumen Juris, 2014.

GUERRA, Y. A instrumentalidade no trabalho do assistente social. 2007. Disponível em: <http://www.unirio.br/unirio/cchs/ess/Members/altineia.neves/instrumentos-e-tecnicas-em-servico-social/guerra-yolonda-a-instrumentalidade-no-trabalho-do-assistente-social/view>. Acesso em: 15 maio 2018.

IAMAMOTO, M. V. Projeto profissional, espaços ocupacionais e trabalho do assistente social na atualidade. In: CFESS. Atribuições privativas do/a assistente social em questão. 1. ed. ampl. Brasília: CFESS, 2012. 
JESUS, D. M.; CARBONIERI, D.; NIGRO, C. M. C. (Orgs.). Estudos sobre gênero: identidades, discurso e educação — homenagem a João W. Nery. Campinas: Pontes Editores: 2017.

JESUS, J. G. de. Orientações sobre identidade de gênero: conceito e termos. Brasília, 2012.

LESSA, S. Mundos dos homens: trabalho e ser social. 3. ed. São Paulo: Instituto Lukács, 2012.

MARTINELLI, M. L. Reflexões sobre o Serviço Social e projeto ético-político profissional. Revista Emancipação, Paraná, ano 6, n. 1, 2006.

A pergunta pela identidade profissional do Serviço Social: uma matriz de análise. Serviço Social \& Saúde, Campinas, v. 12, n. 2 (16), p. 145-156, 2013. Disponível em: $<$ https://periodicos.sbu.unicamp.br/ojs/index.php/sss/article/view/8639491>. Acesso em: 24 ago. 2016,

MINISTÉRIO DA SAÚDE: Processo transexualizador no SUS. Disponível em: <http:// portalms.saude.gov.br/atencao-especializada-e-hospitalar/especialidades/processo-transexualizador-no-sus>. Acesso em: 16 out. 2017.

MISKOLCI, R.; PELÚCIO, L. Fora do sujeito e fora do lugar: reflexões sobre a performatividade a partir de uma etnografia entre travestis. Gênero, Niterói, v. 7, n. 2, 1. sem. 2007. Disponível em: <http://www.revistagenero.uff.br/index.php/revistagenero/article/ view/155/98>. Acesso em: 16 out. 2018.

MOREIRA, R. Sociabilidade e espaço: as formas de organização geográfica das sociedades na era da terceira revolução industrial — um estudo de tendências. Agrária, São Paulo, n. 2, 2005.

NOGUEIRA, L. As determinações patriarcais-heterossexistas da sociedade capitalista. In:__ et al. Hasteemos a bandeira colorida: diversidade sexual e de gênero no Brasil.

São Paulo: Expressão Popular, 2018.

ROCHA, E. F.; SANTOS, T. F. S. Transexualidade e travestilidade: contribuições do serviço social no exercício da cidadania. In: OLIVEIRA, Antonio Deusivam; PINTO, Cristiano Rosalino Braule (Orgs.). Transpolíticas públicas. Campinas: Papel Social, 2017.

SANÍCOLA, L. As dinâmicas de rede e o trabalho social. Tradução Durval Cordas. São Paulo: Veras Editora, 2008.

SILVA, L. V.; BARBOSA, B. R. S. N. Preconceito contra usuários do programa transcidadania. In: OLIVEIRA, Antonio Deusivam; PINTO, Cristiano Rosalino Braule (Orgs.). Transpolíticas públicas. Campinas: Papel Social, 2017.

SILVA, R. G. L. B. da; BEZERRA, W. C.; QUEIROZ, S. B. de. Os impactos das identidades travestis e transexuais na sociabilidade de travestis e mulheres transexuais. Revista de Terapia Ocupacional, São Paulo, v. 26, n. 3, 2015. Disponível em: <http://www.revistas. usp.br/rto/article/view/88052>. Acesso em: 18 abr. 2018.

TAGLIAMENTO, G. Direitos humanos e a saúde: a efetivação de políticas públicas voltadas à saúde integral da população trans. In: SENA, Ana Gabriela Nascimento; SOUTO, Kátia Maria Barreto (Orgs.). Transexualidade e travestilidade na saúde. Brasília: Ministério da Saúde, 2015. 
TENÓRIO, L. F. P. Demanda de uma lei de identidade de gênero brasileira: PLC n. 5.002/2013 - Lei João W. Nery. In: JESUS, Dánie Marcelo de; CARBONIERI, Divanize; NIGRO, Cláudia Maria Ceneviva (Orgs.). Estudos sobre gênero: identidades, discurso e educação - homenagem a João W. Nery. Campinas: Pontes Editores, 2017.

VENTURA, M. A transexualidade no tribunal: saúde e cidadania. Rio de Janeiro: Eduerj, 2010. (Sexualidade, gênero e sociedade).

ZEGER, I. Direito LBGTI: perguntas e respostas. São Paulo: Mescla, 2016.

\section{Sobre as autoras}

Thais Felipe Silva dos Santos - Assistente Social. Mestranda em Serviço Social pela Pontifícia Universidade Católica de São Paulo.

E-mail: thaislipe@gmail.com

Maria Lúcia Martinelli - Assistente social e docente da Pontifícia Universidade Católica de São Paulo (PUC-SP).

E-mail: mlmartinelli@terra.com.br 